\title{
Prediction of Cancer Drug Resistance and Implications for Personalized Medicine
}

\author{
Manfred Volm ${ }^{1}$ and Thomas Efferth ${ }^{2 *}$ \\ ${ }^{1}$ Faculty of Medicine, Ruprecht Karls University, Heidelberg, Germany, ${ }^{2}$ Department of Pharmaceutical Biology, Johannes \\ Gutenberg University, Mainz, Germany
}

OPEN ACCESS

Edited by:

Silvia Giordano,

University of Torino, Italy

Reviewed by:

Davide Melisi,

University of Verona, Italy

Marc Poirot,

Institut national de la santé et de la

recherche médicale, France

${ }^{*}$ Correspondence:

Thomas Efferth

efferth@uni-mainz.de

Specialty section:

This article was submitted to Cancer Molecular Targets and Therapeutics, a section of the journal

Frontiers in Oncology

Received: 23 August 2015 Accepted: 30 November 2015

Published: 17 December 2015

Citation:

Volm M and Efferth T (2015)

Prediction of Cancer Drug Resistance and Implications for Personalized

Medicine.

Front. Oncol. 5:282.

doi: 10.3389/fonc.2015.00282
Drug resistance still impedes successful cancer chemotherapy. A major goal of early concepts in individualized therapy was to develop in vitro tests to predict tumors' drug responsiveness. We have developed an in vitro short-term test based on nucleic acid precursor incorporation to determine clinical drug resistance. This test detects inherent and acquired resistance in vitro and transplantable syngeneic and xenografted tumors in vivo. In several clinical trials, clinical resistance was predictable with more than $90 \%$ accuracy, while drug sensitivity was detected with less accuracy ( 60\%). Remarkably, clinical cross-resistance to numerous drugs (multidrug resistance, broad spectrum resistance) was detectable by a single compound, doxorubicin, due to its multifactorial modes of action. The results of this predictive test were in good agreement with predictive assays of other authors. As no predictive test has been established as yet for clinical diagnostics, the identification of sensitive drugs may not reach sufficiently high reliability for clinical routine. A meta-analysis of the literature published during the past four decades considering test results of more than 15,000 tumor patients unambiguously demonstrated that, in the majority of studies, resistance was correctly predicted with an accuracy between 80 and 100\%, while drug sensitivity could only be predicted with an accuracy of $50-80 \%$. This synopsis of the published literature impressively illustrates that prediction of drug resistance could be validated. The determination of drug resistance was reliable independent of tumor type, test assay, and drug used in these in vitro tests. By contrast, chemosensitivity could not be predicted with high reliability. Therefore, we propose a rethinking of the "chemosensitivity" concept. Instead, predictive in vitro tests may reliably identify drug-resistant tumors. The clinical consequence imply to subject resistant tumors not to chemotherapy, but to other new treatment options, such as antibody therapy, adoptive immune therapy, hyperthermia, gene therapy, etc. The high accuracy to predict resistant tumors may be exploited to develop new strategies for individualized cancer therapy. This new concept bears the potential of a revival of predictive tests for personalized medicine.

Keywords: chemotherapy, drug resistance, individualized therapy, survival times 


\section{INTRODUCTION}

Chemotherapy of malignant tumors is essentially based on the results of prospective, randomized, double-blind phase III studies and corresponding clinical guidelines. However, the clinical response of the individual patient still remains uncertain, although the statistical probability of treatment success is known within large groups of patients from clinical studies. Tumors differ in their molecular architecture and biological behavior from patient to patient and even within the same tumor. There is a large heterogeneity between different subpopulations of tumor cells.

Drug resistance is a major reason for failure of cancer chemotherapy. In present clinical practice, drug resistance can only be recognized during larger periods of treatment. It, therefore, would be of great value for each individual patient to determine resistance before commencing treatment with antineoplastic substances. In nearly $50 \%$ of all cancer cases, resistance to chemotherapy already exists before drug treatment (1). Meanwhile, the knowledge of various resistance mechanisms has increased over the years (2, $3)$. While the responsiveness of tumor cells to targeted anticancer drugs (e.g., HER2- or estrogen-receptor-targeting small molecules) can be predicted by pre-therapeutic determination of their corresponding targets, the situation is more complicated for clinically long established cytotoxic drugs, where the molecular targets are either less well-defined or which have broader modes of action. Here, diagnostic tests are desirable to predict the response of tumors to treatment. If a tumor is resistant, therapy might only give rise to toxic effects in various normal tissues without having any major influence on tumor growth (4). The question therefore arises, whether the general clinical recommendations are optimal or whether they need to be improved by resistance testing.

Many different methods to assay sensitivity or resistance of tumors to chemotherapy have been developed over the last decades $(5,6)$. We used a test in which a cell suspension is prepared from fresh tumor biopsies. The cells are incubated over $3 \mathrm{~h}$ with cytostatic test drugs and the uptake of radioactive nucleic acid precursors $\left({ }^{3} \mathrm{H}\right.$-thymidine or ${ }^{3} \mathrm{H}$-uridine) is determined during the last hour of incubation $(7,8)$. The important advantages of our test procedure are (1) its simplicity, (2) that the cells do not need to be long-term cultured before testing, and (3) that practically all tumor types can be tested. This review gives a synopsis of this test system.

\section{Detection of Acquired Resistance}

The usefulness of any resistance test depends on the degree, to which in vitro results are correlated with clinical results. To prove an in vitro short-term test to detect drug resistance, we generated different tumor lines, which were resistant toward doxorubicin, daunorubicin, cytosine-arabinoside, or cyclophosphamide (9, 10). As exemplarily shown in Figure 1A, sensitive and doxorubicin-resistant sarcoma 180 ascites tumor cells grown in mice were used. After treatment with doxorubicin over 25 passages, resistance to this drug was developed in animals (Figure 1A, left). This doxorubicin resistance was also detectable using this in vitro short-term test (Figure 1A, middle). Upon doxorubicin treatment, mice bearing resistant (pre-treated) tumor cells revealed significantly shorter survival times than mice with nonpre-treated tumor cells.

In addition to determination of resistance at a given time point, it was also possible to detect gradual increase or decrease during the development or reversion of resistance in tumor lines (12).

\section{Detection of Inherent Resistance}

Walker carcinosarcoma and neurosarcoma both grown subcutaneously as solid tumors in rats provide suitable models as rapidly and slowly growing tumors, respectively. If left untreated, rats bearing Walker carcinosarcoma survived for 10 days and those bearing neurosarcoma for 10 weeks. The tumors responded to drug treatment in a growth rate-dependent manner. For example, doxorubicin had only weak effects on neurosarcoma, whereas the growth of Walker carcinosarcoma was appreciably inhibited by the same concentrations of doxorubicin (Figure 1B, left). This different proliferation-dependent sensitivity was also observed in the in vitro short-term test (Figure 1B, middle). We have obtained similar results with other transplantation tumors (adenocarcinoma, sarcoma S180, melanoma FIII, and multiple myeloma) grown in different species (mouse, rat, and hamster) (Figure 1B, right) (7).

The results obtained in few transplantation tumors were confirmed in large panels of animal and human carcinomas. Some carcinomas were very strongly affected by doxorubicin, whereas others showed no or only moderate effects. This variable tumor response to doxorubicin was correlated with the proliferation rate of these tumors (Figure 1C, left). A comparison between animal transplantation tumors and clinical human tumor specimens showed that animal tumors tend to be more sensitive than human ones (Figure 1C, middle). In general, tumors with high incorporation rates of nucleic acid precursors showed more pronounced inhibitory effects and vice versa (13).

To explore the relevance of proliferation-dependent drug response for patient survival, we investigated fresh surgical specimens of previously untreated ovarian carcinomas (Figure 1C, right) (11). All patients underwent surgery and subsequent chemotherapy, and all patients had a minimum of 5 years of follow up. Patients with highly proliferative tumors (proportion of SG2M-phase cells $>17 \%$ as measured by flow cytometry) had shorter survival times than those with low proliferating tumors (proportion of SG2M-phase cells $\leq 17 \%)(p=0.01)$. Similar results were obtained with lung carcinomas (14). This is in agreement with the general clinical observation that cancer chemotherapy is most successful, if applied for rapidly growing malignant cells (Figure 1C, right) (13).

\section{CLINICAL STUDIES}

Survival curves differed, if patients were distributed into two groups on the basis of the in vitro short-term test with doxorubicin. Patients with in vitro resistant tumors died sooner than in vitro sensitive ones. Lung cancer patients, who refused chemotherapy lived on average only as long as patients with in vitro resistant tumors (8).

Results of these clinical pilot studies encouraged us to start a controlled clinical trial predominantly in ovarian and lung cancer, 
A Acquired drug resistance
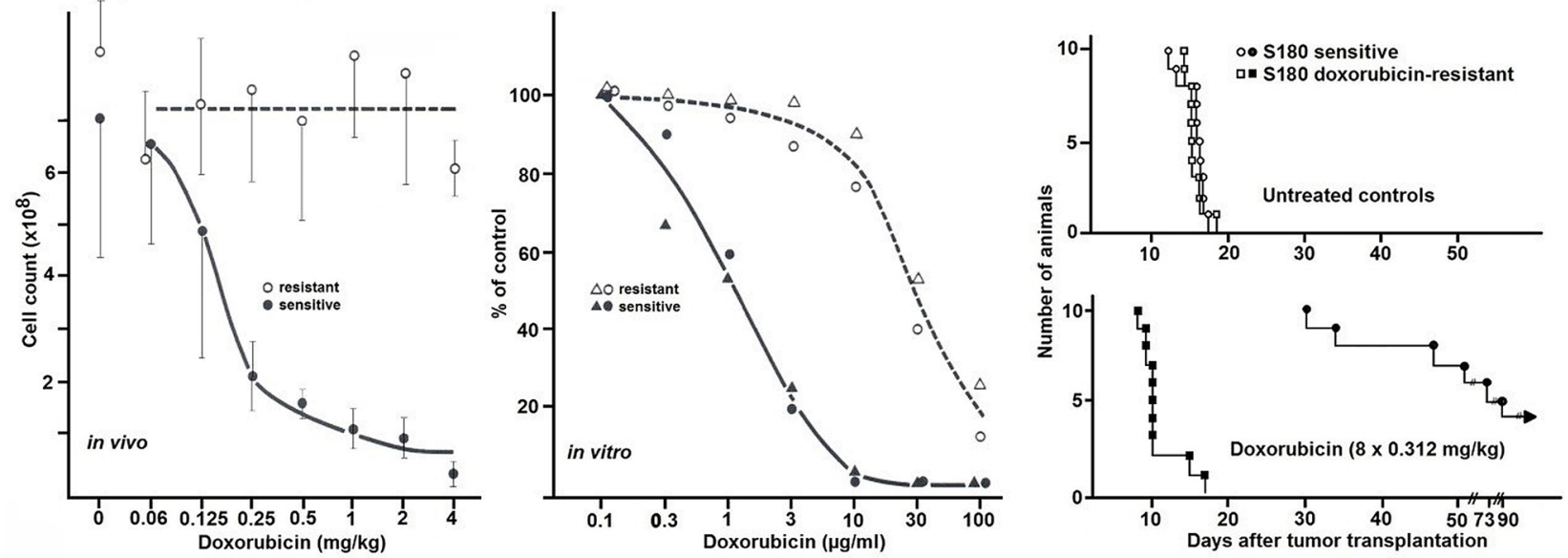

B Inherent drug resistance
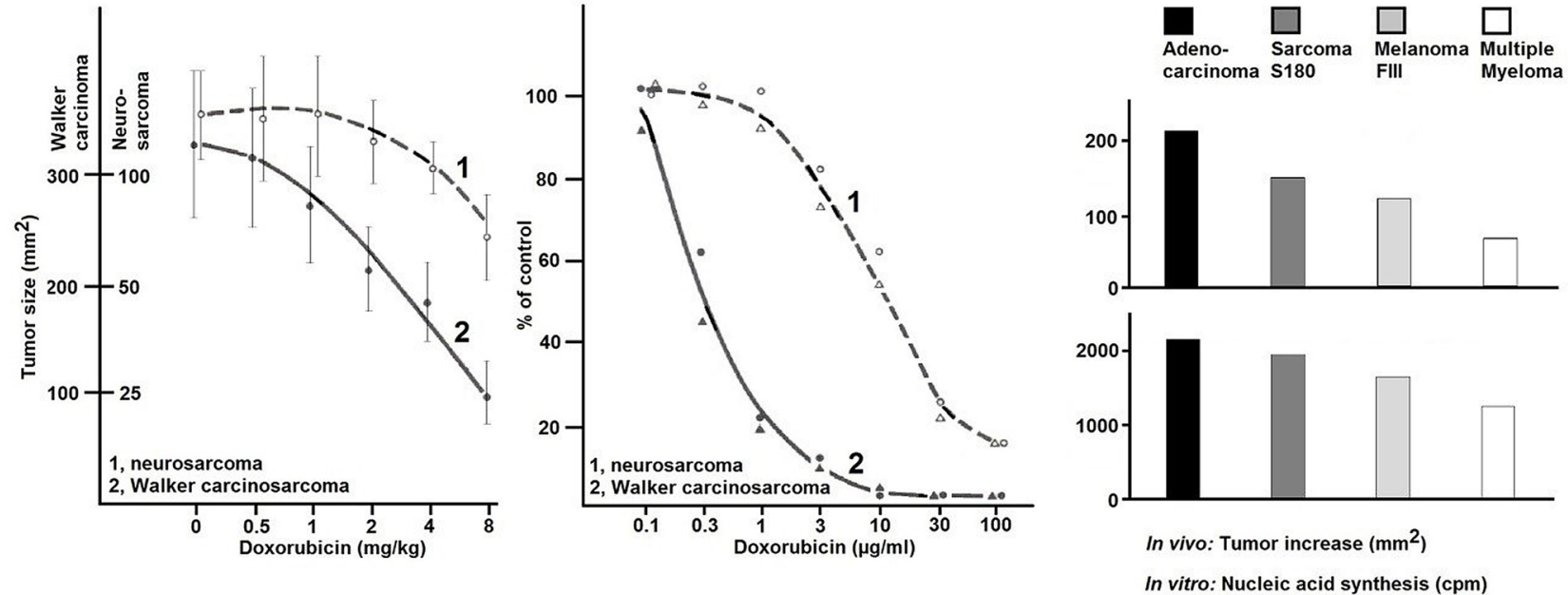

\section{Proliferation-dependent drug resistance}
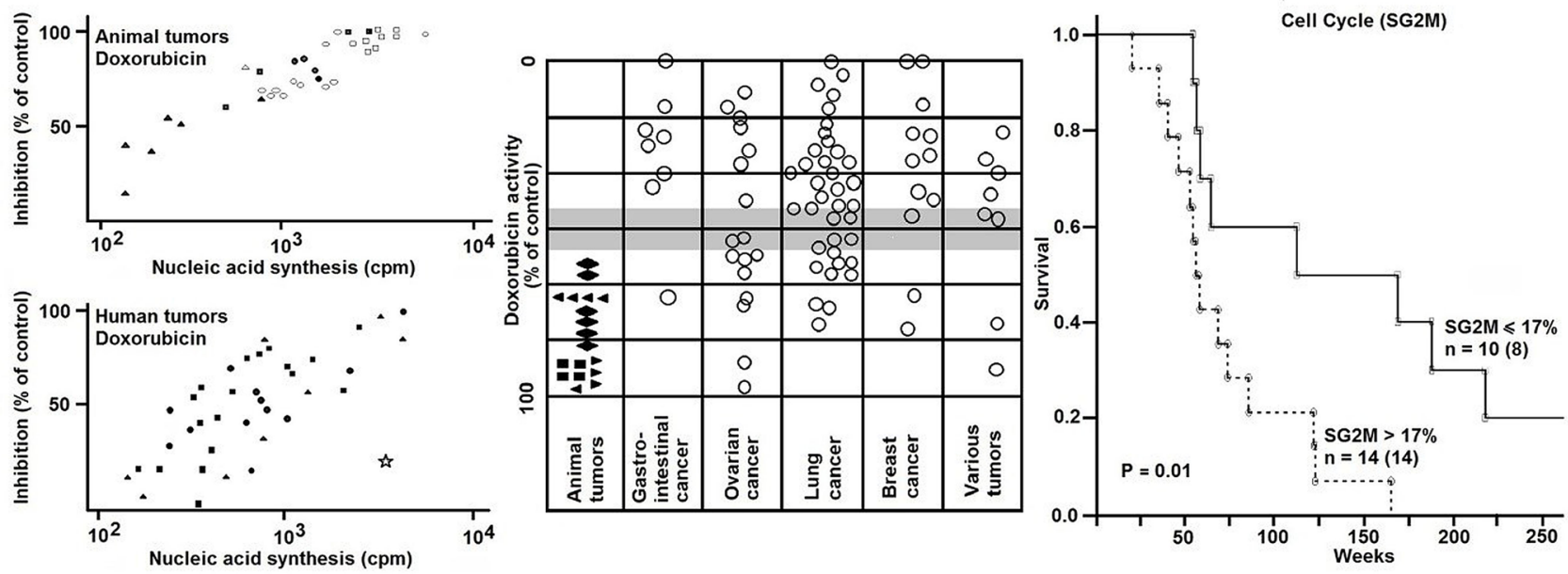

FIGURE 1 | 


\begin{abstract}
FIGURE 1 | Continued
(A) The effects of different doxorubicin concentrations on doxorubicin-resistant or doxorubicin-sensitive ascites tumor cells of murine sarcoma 180 in vivo (left). Resistant tumor cells grown in mice were treated with doxorubicin $(3 \times 0.5 \mathrm{mg} / \mathrm{kg} \mathrm{BW}$ per week) during 25 passages. The cytotoxic effect was measured by determination of the cell count. Average values \pm SD are from seven tumors at each point. Corresponding results (middle) using the in vitro short-term test. After incubation of the tumor cells with different concentration of doxorubicin for $2 \mathrm{~h}$, radioactive nucleic precursors $\left({ }^{3} \mathrm{H}\right.$-uridine) were added for another hour. The non-incorporated radioactivity was extracted and the incorporated radioactivity determined by liquid scintillation counting. Uptake values were expressed as percentages of controls. Right: survival curves of mice bearing sensitive or resistant sarcoma S180 cells without or with doxorubicin treatment. Without therapy, the survival times for the animal with sensitive or resistant tumors were the same. With therapy, the survival times of both groups were significantly different. $n=60$ mice. Data were taken from Ref. (9). (B) The effect of different concentrations of doxorubicin in slowly growing ( $1=$ neurosarcoma) and rapidly growing $(2=$ Walker carcinosarcoma) animal tumors. Left: tumor size under therapy (square millimeter). Average values \pm SD were from seven tumors at each point $(n=84$ rats). Middle: ${ }^{3} \mathrm{H}$-uridine incorporation in vitro. Values (\% of controls) were the averages from two tumors with duplicate determinations. Data were taken from Ref. (7). Right: relationship between tumor growth and cytostatic activity in various transplantation tumors (adenocarcinoma, sarcoma S180, melanoma FIII, and multiple myeloma) grown in different species (mouse, rat, and hamster). Right, top: tumor increase in vivo within 1 day (square millimeter). Right, bottom: ${ }^{3} \mathrm{H}$-Thymidine incorporation in vitro (cpm). Data were taken from Ref. (7). (C) The proliferation-dependent drug resistance in animal and human tumors. The variable tumor response to doxorubicin in vitro was assayed with a fixed concentration of $10^{-2} \mathrm{mg} / \mathrm{ml}$ (left and middle). Right: survival curves of patients with ovarian carcinomas subdivided according to the cell cycles phases (proportion of SG2M-phases $\leq$ or >17\%). Flow cytometric analyses were carried out using an ICP-22 (PHYWE AG, Göttingen, Germany). For measurements of DNA content, a mixture of propidiumiodide and 4-6-diamidino-2-phenylindole was simultaneously applied with RNAse after methanol fixation and protease digestion. Data were taken from Ref. (11).
\end{abstract}

but also in other tumor types (Figure 2). In a multi-centric trial conducted by nine different hospitals, results obtained by the in vitro short-term test were compared with the clinical response of patients (15). Seventy-two patients with ovarian carcinoma, 24 patients with lung carcinoma, and 18 patients with various other tumor types were treated according to standardized therapy schedules (5-fluorouracil and cyclophosphamide for ovary carcinoma, cyclophosphamide, methotrexate, 5-fluorouracil for lung cancer) (Figure 2A). The remaining patients received different therapy regimens. Using the in vitro short-term test, dose-response curves were generated for doxorubicin as well as 5-fluorouracil and 4-OOH-cyclophosphamide (the in vitro active metabolite of cyclophosphamide). Remarkably, doxorubicin was most accurate compound compared to the other two drugs to predict clinical responsiveness to chemotherapy (Figure 2A) independent of the specific therapy regimen.

Summing up the results of all tumors studied in this trial, we have 151 matched comparisons of in vitro test results and clinical response rates to chemotherapy (Figure 2A). Of them, 76 had been classified as resistant and 75 as sensitive by the in vitro shortterm test. Of the 76 tumors resistant in vitro, 56 were clinically progressive (73\%), two were in remission and 19 (25\%) showed no change. The 75 in vitro sensitive tumors showed the following clinical courses: 18 (24\%) were progressive, 40 (53\%) were in remission, and 17 (23\%) were unchanged. If only strict clinical criteria (progression or remission) were applied and compared to the in vitro test results, 55 of the 57 in vitro resistant tumors were clinically progressive (96\%) and only 40 of 58 in vitro sensitive tumors reached clinical remission (69\%) (Figure 2A). Thus, drug resistance was predictable with high accuracy, but not drug sensitivity. Furthermore, drug resistance has been detected in vitro by doxorubicin with high accuracy, even if this substance had not been included in the clinical therapy regimens. By contrast, it was not possible to predict in vitro drug-specific sensitivity in primary, non-pre-treated human carcinomas with the same degree of accuracy.

To see whether or not our own results reflect the situation observed by other investigators, we performed a survey of all drug sensitivity/resistance results published since 1980 until today. As a first step, we extracted the test results of more than 3600 cancer patients and compared the prediction of sensitivity or resistance in vitro with the clinical treatment response (Table 1, upper part). The vast majority of publications reported that the prediction of drug resistance was possible with much higher accuracy than prediction of drug sensitivity. In the majority of studies, resistance was correctly predicted with an accuracy between 80 and 100\%, while drug sensitivity could only be predicted with an accuracy of only $50-80 \%$. As a next step, we compared our own evaluation of published data with meta-analyses performed by other authors (Table 1, lower part). The numbers of patients of all published papers exceeded 15,000. Remarkably again, drug resistance could be predicted with high reliability, but not sensitivity. This synopsis of the published literature of four decades impressively illustrates that the concept of prediction of chemosensitivity was not validated. By contrast, the determination of drug resistance was reliable independent of tumor type, test assay, and drug used in these in vitro tests.

Figures 2B,C show that the in vitro test results were in good agreement with patients' survival. Patients, whose tumors were resistant in the in vitro short-term test, died earlier than patients, whose tumors were in vitro sensitive. This cooperative clinical trial confirmed the feasibility to predict resistance of cancer in vitro before starting chemotherapy and the relevance for clinical treatment. In a further study (Figures 2D,E), we investigated surgical adenocarcinoma specimens of the lung (stage III) and compared the in vitro short-term test results with survival of patients treated with chemotherapy (16). Thirty-two patients with previously untreated adenocarcinoma of the lung (stage III, $\mathrm{pT}, \mathrm{pN}$ ) were included in this investigation. The minimum follow up time was 5 years. Fourteen patients were only treated by surgical procedures (group S), and 18 patients were additionally treated with cytotoxic drugs (CT group). The chemotherapy protocols used were (a) doxorubicin/cyclophosphamide/vincristine and (b) BCNU/5-fluorouracil, and (c) cisplatinum/vindesine. The survival curves did not differ between the $S$ and CT groups ( $\log$-rank $p=0.63$; rank-sum $p=0.39$ ) (Figure 2D). However, if we reanalyzed the same data on the basis of the in vitro shortterm test results, a different pattern emerged. The CT patients, 
A
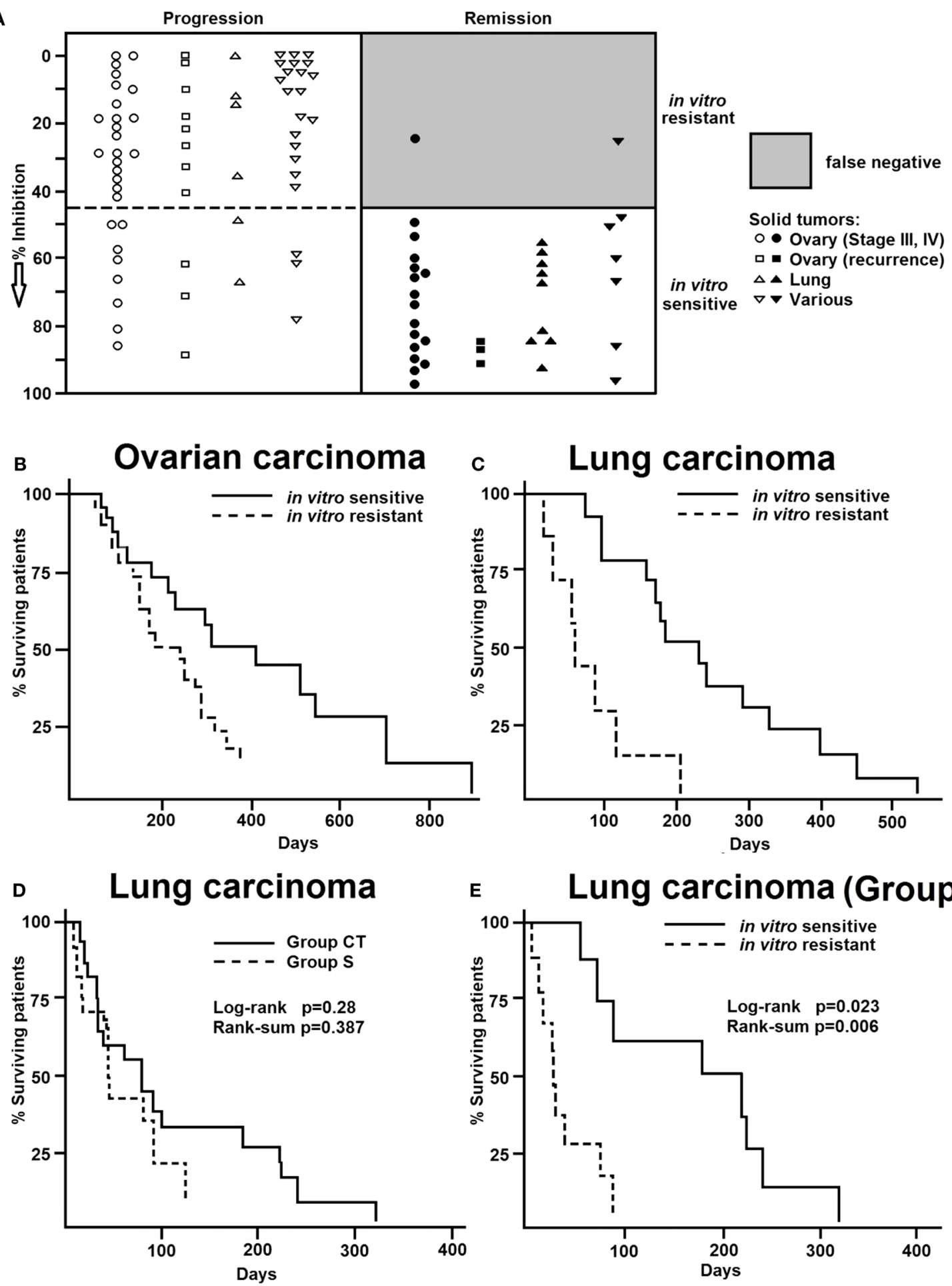

FIGURE 2 | (A) Comparison of results of the in vitro short-term test and clinical chemotherapy of human tumors. Values represent the inhibition (\%) of ${ }^{3} \mathrm{H}$-uridine incorporation. Closed symbols, tumors responsive to clinical chemotherapy. Open symbols, Tumors non-responsive to clinical chemotherapy. Data were taken from Ref. (15). Overall survival curves of patients with (B) ovarian carcinoma or (C) lung carcinoma separated into either resistant or sensitive groups according to the in vitro short-term test results. Data were taken from Ref. (15). (D) Of the 32 patients with previously untreated adenocarcinoma of the lung (stage III), 14 were treated with surgery alone (group S) and 18 were treated with surgery plus chemotherapy (group CT). The survival curves were not different between the S and CT groups (log-rank $p=0.63$, rank-sum $p=0.39$ ). (E) However, when the same data were analyzed on the basis of the in vitro short-term test, a different pattern appeared. CT patients with in vitro sensitive tumors were lived significantly longer than those with resistant tumors (log-rank $p=0.023$, rank-sum $p=0.006)$. Data were taken from Ref. (16). 
TABLE 1 | Predictive value of drug resistance assays.

Assay Tumor type Reference

\section{Original investigations}

Tumor clonogenic assay

${ }^{3} \mathrm{H}$-thymidine and ${ }^{3} \mathrm{H}$-uridine

incorporation

Extreme drug resistance assay

Fluroescent cytofootprint assay

Tumor clonogenic assay

ATP luminescence assay

Fluroescent cytofootprint assay

MTT assay

ATP luminescence assay

MTT assay

${ }^{3} \mathrm{H}$-thymidine incorporation

ATP luminescence assay

Sulforhodamine B assay

${ }^{3} \mathrm{H}$-thymidine incorporation

Extreme drug resistance

Fluroescent cytofootprint assay

ATP luminescence assay

${ }^{3} \mathrm{H}$-uridine incorporation

MTT assay

MTT assay

${ }^{3} \mathrm{H}$-thymidine incorporation, tumor

clonogenic assay

${ }^{3} \mathrm{H}$-thymidine incorporation

MTS assay

ATP luminescence assay

ATP luminescence assay

ATP luminescence assay

Tumor clonogenic assay

Tumor clonogenic assay

Tumor clonogenic assay

Tumor clonogenic assay

ATP luminescence assay

Tumor clonogenic assay

Tumor clonogenic assay

Dye exclusion assay

Collagen gel droplet embedded

culture drug sensitvity test (CD-DST)

Tumor clonogenic assay

Flow cytometry of DNA integrity

Dye exlusion assay

MTT assay

Tumor clonogenic assay,

${ }^{3} \mathrm{H}$-thymidine incorporation

${ }^{3} \mathrm{H}$-tymidine in corporation

${ }^{3} \mathrm{H}$-thymidine incorporation

CD-DST

Tumor clonogenic assay of

xenograft tumors

ChemoFx ${ }^{\otimes}$ test
Ovarian $\mathrm{Ca}$

Ovarian $\mathrm{Ca}$

Ovarian $\mathrm{Ca}$

Ovarian $\mathrm{Ca}$

Ovarian $\mathrm{Ca}$

Ovarian $\mathrm{Ca}$

Ovarian $\mathrm{Ca}$

Ovarian $\mathrm{Ca}$

Ovarian $\mathrm{Ca}$

Ovarian $\mathrm{Ca}$

Ovarian $\mathrm{Ca}$

Ovarian $\mathrm{Ca}$

Peritonitis carcinomatosa

of ovarian $\mathrm{Ca}$

Breast $\mathrm{Ca}$

Breast $\mathrm{Ca}$

Breast $\mathrm{Ca}$

Breast $\mathrm{Ca}$

Breast Ca

Breast $\mathrm{Ca}$

Breast Ca

Gynecological Ca

Gynecological Ca

Gynecological $\mathrm{Ca}$

Gastric Ca

Gastrointestinal Ca

Esophageal $\mathrm{Ca}$

Liver Ca and liver

metastasis

Liver Ca

Melanoma

Melanoma

Melanoma

Lung cancer

Lung cancer

Lung Ca (SCLC)

Lung Cancer (NSCLC)

Glioma

Glioma

Acute leukemia

Acute leukemia

Multiple myeloma

Diverse

Diverse

Diverse

Diverse

Squamous cell $\mathrm{Ca}$, adeno $\mathrm{Ca}$
44

99\% resistance prediction; 62\% sensitivity prediction $84 \%$ resistance prediction; $79 \%$ sensitivity prediction

100\% resistance prediction; $58 \%$ sensitivity prediction 96\% resistance prediction; $71 \%$ sensitivity prediction $83 \%$ resistance prediction; $50 \%$ sensitivity prediction $>90 \%$ resistance prediction (70 untreated, 30 refractory) $100 \%$ resistance prediction; $56 \%$ sensitivity prediction $85 \%$ resistance prediction; $65 \%$ sensitivity prediction $89 \%$ resistance prediction; $66 \%$ sensitivity prediction $83 \%$ resistance prediction

$100 \%$ resistance prediction; $60 \%$ sensitivity prediction $79 \%$ resistance prediction; $60 \%$ sensitivity prediction $89.5 \%$ resistance prediction; $62.5 \%$ sensitivity prediction

$81 \%$ resistance prediction; $75 \%$ sensitivity prediction $100 \%$ resistance prediction; $47 \%$ sensitivity prediction $100 \%$ resistance predition; $91 \%$ sensitivity prediction $86 \%$ resistance prediction; $90 \%$ sensitivity prediction 94\% resistance prediction; $71 \%$ sensitivity prediction $80 \%$ resistance prediction; $61 \%$ sensitivity prediction $100 \%$ resistance prediction; $76.7 \%$ sensitivity prediction $<50 \%$ sensitivity prediction; $90 \%$ resistance prediction

$72 \%$ resistance prediction; $85 \%$ sensitivity prediction 93.3\% resistance prediction; $86.7 \%$ sensitivity prediction 95.7\% resistance prediction; $46.2 \%$ sensitivity prediction $100 \%$ resistance prediction; $64 \%$ sensitivity prediction $68.8 \%$ resistance prediction; $77.8 \%$ sensitivity prediction $71 \%$ resistance prediction; $55 \%$ sensitivity prediction

91\% resistance prediction; $77 \%$ sensitivity prediction Retrospective: 100\% resistance prediction; 38\% sensitivity prediction

Prospective: 100\% resistance prediction; $60 \%$ sensitivity prediction

83.9\% resistance prediction; $36.4 \%$ sensitivity prediction $91 \%$ resistance prediction; $60 \%$ sensitivity prediction $86 \%$ resistance prediction; $83 \%$ sensitivity prediction $82 \%$ resistance prediction; $55 \%$ sensitivity prediction $100 \%$ resistance prediction; $72.7 \%$ sensitivity prediction

$100 \%$ resistance prediction; $60 \%$ sensitivity prediction $81 \%$ resistance prediction; $86 \%$ sensitivity prediction $33,3 \%$ resistance prediction; $86.7 \%$ sensitivity prediction $77,8 \%$ resistance prediction; $91.3 \%$ sensitivity prediction $73 \%$ sensitivity prediction; $83 \%$ resistance prediction

$100 \%$ resistance prediction; $46.2 \%$ sensitivity prediction $93 \%$ resistance prediction; $67 \%$ sensitivity prediction $100 \%$ resistance prediction; $80 \%$ sensitivity prediction $62 \%$ sensitivity prediction; $97 \%$ resistance prediction

58\% resistance prediction; $87 \%$ sensitivity prediction
Alberts et al. (17)

Khoo et al. (18)

Kern et al. (19)

Blackman (20)

Federico et al. (21)

Andreotti et al. (22)

Csoka et al. (23)

Taylor et al. (24)

Konecny et al. (25)

Taylor et al. (26)

Hetland et al. (27)

Neubauer et al. (28)

Arienti et al. (29)

Daidone et al. (30)

Kern (19)

Blackman (20)

Kochli et al. (31)

Elledge et al. (32)

Xu et al. (33)

Xu et al. (34)

Eidtmann et al. (35)

Khoo et al. (36)

O'Toole et al. (37)

Kim et al. (38)

Kawamura et al. (39)

Hirai et al. (40)

Link et al. (41)

Link et al. (42)

Tveit et al. (43)

Tveit et al. (43)

Ugurel et al. (44)

Kitten et al. (45)

Bertelsen et al. (46)

Gazdar et al. (47)

Kawamura et al. (48)

Alonso (1984) (49)

Iwadate et al. (50)

Hwang et al. (51)

Hwang et al. (51)

Durie et al. (52)

Sondak et al. (53)

Wada et al. (54)

Kobayashi et al. (55)

Fiebig et al. (56)

Grigsby et al. (57) 
TABLE 1 | Continued

\begin{tabular}{|c|c|c|c|c|}
\hline Assay & Tumor type & $\begin{array}{l}\text { No. of } \\
\text { patients }\end{array}$ & Predictive accuracy & Reference \\
\hline \multicolumn{5}{|l|}{ Reviews } \\
\hline Tumor clonogenic assay & Diverse (review) & & $96 \%$ resistance prediction; $62 \%$ sensitivity prediction & Salmon et al. (58) \\
\hline Tumor clonogenic assay & Diverse (review) & $>1500$ & 92\% resistance prediction; $57 \%$ sensitivity prediction & Bertelsen et al. (59) \\
\hline Tumor clonogenic assay & Diverse (review) & & $91 \%$ resistance prediction; $71 \%$ sensitivity prediction & Salmon et al. (60) \\
\hline Diverse & Glioma (review) & & $100 \%$ resistance prediction; $50-70 \%$ sensitivity prediction & Kimmel et al. (61) \\
\hline Subrenal capsule assay & Diverse (review) & 1400 & $73 \%$ resistance prediction; $91 \%$ sensitivity prediction & Bodgen and Cobb (62) \\
\hline Diverse & $\begin{array}{l}\text { Review of } 54 \text { retrospective } \\
\text { studies }\end{array}$ & 2300 & $91 \%$ resistance prediction; $69 \%$ sensitivity prediction & von Hoff et al. (63) \\
\hline Fluorescent cytoprint assay & Diverse (review) & & $91 \%$ resistance prediction; $86 \%$ sensitivity prediction & Meitner et al. (64) \\
\hline Diverse & Diverse (review) & 1100 & 93\% resistance prediction; $46.7 \%$ sensitivity prediction & Kondo et al. (65) \\
\hline CD-DST & Diverse & 183 & $88.8 \%$ resistance prediction; $79.8 \%$ sensitivity prediction & Kobayashi et al. (66) \\
\hline Tumor clonogenic assay & Diverse (review) & 2300 & $91 \%$ resistance prediction; $69 \%$ sensitivity prediction & Fiebig et al. (56) \\
\hline Tumor clonogenic assay & Diverse (review) & 66 & $92 \%$ resistance prediction; $62 \%$ sensitivity prediction & Fiebig et al. (56) \\
\hline Diverse assays & Ovarian Ca (review) & 1101 & $93 \%$ resistance prediction; $46.6 \%$ sensitivity prediction & $\begin{array}{l}\text { Kubota and Weisenthal } \\
(67)\end{array}$ \\
\hline Diverse assays & $\begin{array}{l}\text { Diverse tumor types } \\
\text { (review) }\end{array}$ & 4092 & $90.3 \%$ resistance prediction; $71,7 \%$ sensitivity prediction & Blumenthal et al. (6) \\
\hline Diverse & Review of 86 studies & 1945 & $87.4 \%$ resistance prediction; $80.0 \%$ sensitivity prediction & Weisenthal (68) \\
\hline
\end{tabular}

whose tumors were in vitro sensitive lived significantly longer than those with in vitro resistant tumors $(\log$-rank $p=0.023$, rank-sum $p=0.006$ ) (Figure $2 \mathrm{E}$ ). The median survival times were 185 weeks for patients with in vitro sensitive tumors and 31 weeks for the patients with in vitro resistant tumors. Importantly, there was a statistically significant positive correlation $(r=0.7)$ between the degrees of doxorubicin-induced inhibition of ${ }^{3} \mathrm{H}$-uridine uptake and patients' survival times. As expected, the survival times of patients treated with surgery, but not chemotherapy, did not correlate with the in vitro test results (16). Thus, the observed differences in survival times of patients treated with surgery plus chemotherapy were specific and can be attributed to drug therapy.

Again, we have compared our own data with published results of more than 1900 patients in the literature. As shown in Table 2, patients with tumors that appeared as being sensitive in drug resistance testing had a better survival outcome than patients with drug-resistant tumors. This has been observed in the vast majority of patients independent of which tumors they were suffering from or which cytostatic drug has been used for testing.

\section{BROAD SPECTRUM RESISTANCE}

If a tumor responded to doxorubicin by means of the in vitro short-term test, in the majority of cases similar effects can be detected with other cytostatic agents, i.e., tumors insensitive to doxorubicin are also insensitive to other drugs (Figure 3A). Statistically significant correlations existed between the inhibitory effect of doxorubicin, daunorubicin, 5-fluorouracil, actinomycin $\mathrm{D}$, and cyclophosphamide (8). The correlation coefficient for the in vitro activities of doxorubicin and daunorubicin was $r=0.864$ and that for doxorubicin and 5-fluorouracil $r=0.779$. Similar correlations were also observed between the activities of doxorubicin and actinomycin $\mathrm{D}(r=0.907)$ as well as of doxorubicin and cyclophosphamide $(r=0.710)$.
In the 1980s and 1990s, a resistance phenomenon has been investigated termed multidrug resistance (MDR), which is caused by the drug efflux transporter P-glycoprotein. MDR comprises cross-resistance of tumor cells to anthracyclines, Vinca alkaloids, taxanes, and epipodophyllotoxins, but not to alkylating agents and antimetabolites $(88,89)$.

Therefore, we were interested, whether or not the crossresistance profile observed in our approach was compliant with the MDR phenotype (87). We analyzed 59 tumors of different origin for their in vitro resistance to anthracyclines (doxorubicin, daunorubicin), antibiotics (dactinomycin, bleomycin), antimetabolites (5-fluorouracil, methotrexate), epipodophyllotoxins (mitopodozide), and alkylating agents (procarbazine, triaziquone) by means of the in vitro short-term test.

As a next step, we performed hierarchical cluster analysis, which may be more suited for an integrated approach to understand the complexity of drug resistance. All investigated drugs except doxorubicin were subjected to cluster analysis (Figure 3B, left). We divided the dendrogram into six clusters and correlated them with the doxorubicin results. Interestingly, sensitive and resistant tumors were separated in the clusters $\left(p=2.5 \times 10^{-7}\right)$. Clusters 1,5 , and $6(n=31)$ were enriched with doxorubicinresistant tumors $(54 \%)$, whereas clusters 2,3 , and $4(n=28)$ were enriched with doxorubicin-sensitive ones. This indicates that resistance to nine compounds from different drug classes (antibiotics, antimetabolites, epipodophyllotoxins, and alkylating agents) significantly correlated with resistance to doxorubicin. This opens the possibility to predict the responsiveness of tumors to a broad range of cytostatic drugs by using solely doxorubicin as a reference drug. To further explore this phenomenon in a group of tumors of the same tumor type, we investigated 38 lung cancers for their response in vitro to doxorubicin, 5-fluorouracil, and 4-OOH-cyclophosphamide (Figure 3B, middle). Cluster analysis using the data for 5-fluorouracil and 4-OOH-cyclophosphamide allowed the separation of three clusters. Again, we found a 
TABLE 2 | Prognostic value of drug resistance assays.

\begin{tabular}{|c|c|c|c|c|}
\hline Assay & Tumor type & $\begin{array}{c}\text { No. of } \\
\text { patients }\end{array}$ & Prognostic relevance & Reference \\
\hline MTT assay & Ovarian Ca & 120 & Survival benefit of sensitive vs. resistant & Taylor et al. (26) \\
\hline Extreme drug resistance assay & Ovarian Ca & 79 & Survival benefit of sensitive vs. resistant & Holloway et al. (69) \\
\hline 3D-histoculture assay & Ovarian Ca & 164 & Survival benefit of sensitive vs. resistant & Nakada et al. (70) \\
\hline ChemoFx ${ }^{\otimes}$ test & Ovarian $\mathrm{Ca}$ & 147 & Survival benefit of sensitive vs. resistant & Herzog et al. (71) \\
\hline 3D-histoculture assay & Ovarian Ca & 104 & Survival benefit of sensitive vs. resistant & Jung et al. (72) \\
\hline MTT assay & Ovarian $\mathrm{Ca}$ & 120 & Survival benefit of sensitive vs. resistant & Xu et al. (73) \\
\hline 3D-histoculture assay & $\begin{array}{l}\text { Peritonitis } \\
\text { carcinomatosa }\end{array}$ & 18 & Survival benefit of sensitive vs. resistant & Isogai et al. (74) \\
\hline Three-dimensional histoculture & Gastric Ca & 128 & Survival benefit of sensitive vs. resistant & Kubota et al. (75) \\
\hline Three-dimensional histoculture & Gastric Ca & 32 & Survival benefit of sensitive vs. resistant & Furukawa et al. (76) \\
\hline MTT assay & Gastric Ca & 28 & Survival benefit of sensitive vs. resistant & Abe et al. (77) \\
\hline 3D-histoculture assay & Gastric Ca & 100 & No survival benefit of sensitive vs. resistant & Kodera et al. (78) \\
\hline MTT assay & Gastric Ca & 353 & No survival benefit of sensitive vs. resistant & Wu et al. (79) \\
\hline MTT assay & Gastric Ca & 50 & Survival benefit of sensitive vs. resistant & Kubota et al. (80) \\
\hline Three-dimensional histoculture & Colorectal cancer & 29 & Survival benefit of sensitive vs. resistant & Furukawa et al. (76) \\
\hline MTT assay & Colorectal $\mathrm{Ca}$ & 200 & Survival benefit of sensitive vs. resistant & Kabeshima et al. (81) \\
\hline MTT assay & Pancreas $\mathrm{Ca}$ & 14 & Survival benefit of sensitive vs. resistant & Yamaue et al. (82) \\
\hline ATP luminescence assay & Pancreas Ca & 18 & $\begin{array}{l}\text { Sensitive tumors have lower risk of treatment failure than } \\
\text { resistant ones }\end{array}$ & Michalski et al. (83) \\
\hline MTT assay & Esophageal $\mathrm{Ca}$ & 46 & Survival benefit of sensitive vs. resistant & Nakamori et al. (84) \\
\hline ATP luminescence assay & Melanoma & 53 & Survival benefit of sensitive vs. resistant & Ugurel et al. (44) \\
\hline ATP luminescence assay & Melanoma & 14 & Survival benefit of sensitive vs. resistant & Doerler et al. (85) \\
\hline $\begin{array}{l}\text { Collagen gel droplet embedded culture drug } \\
\text { sensitvity test (CD-DST) }\end{array}$ & $\begin{array}{l}\text { Lung cancer } \\
\text { (NSCLC) }\end{array}$ & 49 & Survival benefit of sensitive vs. resistant & Kawamura et al. (48) \\
\hline ATP luminescence assay & Leukemia (ANLL) & 23 & Survival benefit of sensitive vs. resistant & Möllgård et al. (86) \\
\hline
\end{tabular}

statistically significant relationship between resistance to doxorubicin and resistance to the other drugs $\left(p=1.10 \times 10^{-3}\right)$ in 21 leukemia examples. To validate this result on lung cancer as a solid tumor type, we subsequently used leukemia as single cell cancer. Similar to doxorubicin, daunorubicin as anthracycline of choice for leukemia treatment predicted resistance to other drugs (etoposide, cytosine, arabinoside, 6-thio-guanine) as determined by cluster analysis $\left(p=1.29 \times 10^{-4}\right)$ (Figure 3B, right). In addition to a possible value of doxorubicin as reference compound for the in vitro short-term test, another conclusion of these investigations is that tumors exert cross-resistance profiles that are broader than the classical P-glycoprotein-mediated MDR phenotype. Therefore, we have used the term "broad spectrum resistance." Our point of view on clinical drug resistance phenomena has been recently supported by comparable observations described as "pan-resistance" (90).

Our cluster analyses revealed that clusters of sensitive or resistant tumors could be predicted by one single drug, doxorubicin. This speaks for the high predictive power of doxorubicin to detect broad spectrum resistance. The pleiotropic modes of action of doxorubicin might explain, why doxorubicin is capable of predicting broad spectrum resistance.

1. Doxorubicin is transported by P-glycoprotein and, therefore, is involved in the MDR phenotype. Therefore, doxorubicin can predict response to antibiotics, Vinca alkaloids, and epipodophyllotoxins.

2. Doxorubicin inhibits DNA topoisomerase II, which is necessary for cell division. The activity of doxorubicin is dependent on the proliferative activity of tumor cells. Therefore, doxorubicin may predict the responsiveness of tumors to other drugs, which also act in a proliferation-dependent manner, such as antimetabolites, i.e., 5-fluorouracil.

3. The inhibition of DNA topoisomerase II by doxorubicin induces DNA strand breaks. Because alkylating agents also damage DNA, doxorubicin may predict the response to alkylators, such as 4-OOH-cyclophosphamide.

4. Doxorubicin as well as alkylating agents generates reactive oxygen species and radical carbon-centered molecules. This represents another explanation for the predictive power of doxorubicin toward alkylating drugs.

This enables to conduct predictive tumor tests with drugs not included in the therapy schedule. According to our investigations on human tumors, tests using doxorubicin appear to be sufficient to detect drug resistance. Therefore, the in vitro short-term test should be generally not used to find the most effective compound in individual tumors, but merely to determine whether a tumor responds at all to any chemotherapy.

\section{THE MULTIFACTORIAL NATURE OF CANCER DRUG RESISTANCE}

Having in mind that tumors tend to be sensitive or resistant not only to single but also to multiple drugs at the same time, it can be speculated that multiple factors rather than single mechanisms may account for broad spectrum or pan-resistance $(87,90)$. For this reason, we investigated a battery of diverse factors for their expression levels in lung tumors and compared these expressions with the results of the in vitro short-term test. The rationale 


\section{A Cross-resistance}
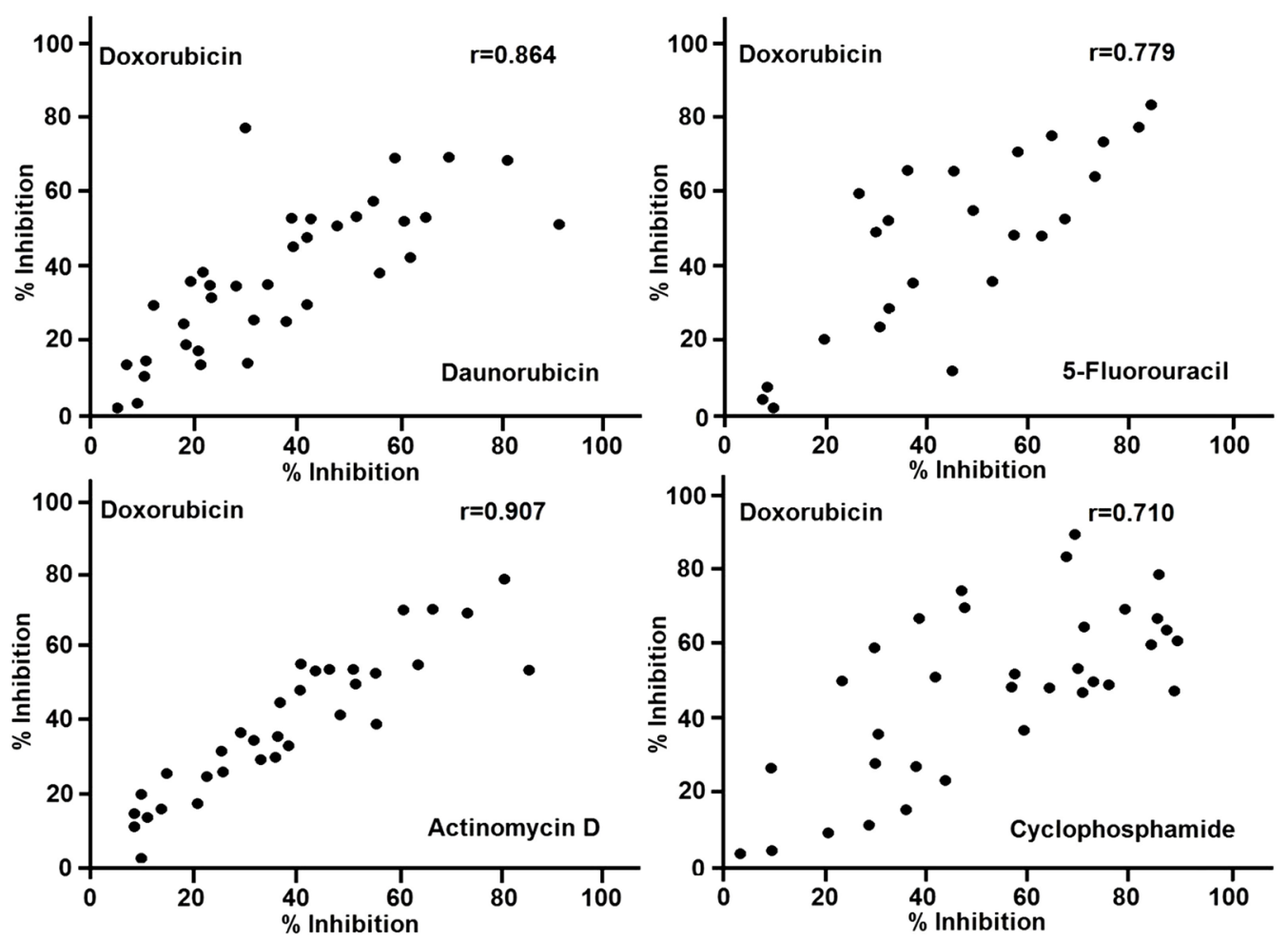

\section{B Cluster Analyses}

Diverse tumors

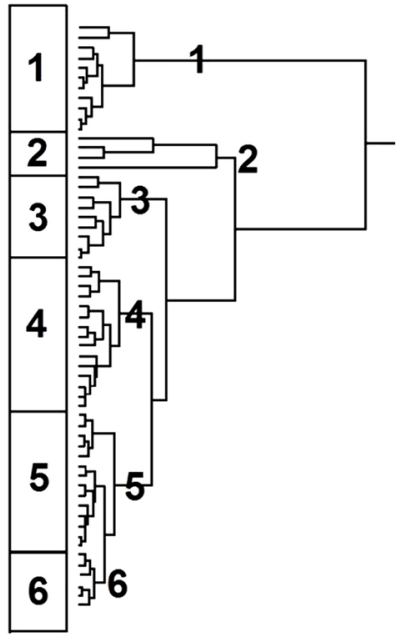

Doxorubicin Clusters Clusters

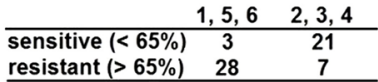

$P=2.54 \times 10^{-7}$ (Fisher exact test)
Lung tumors
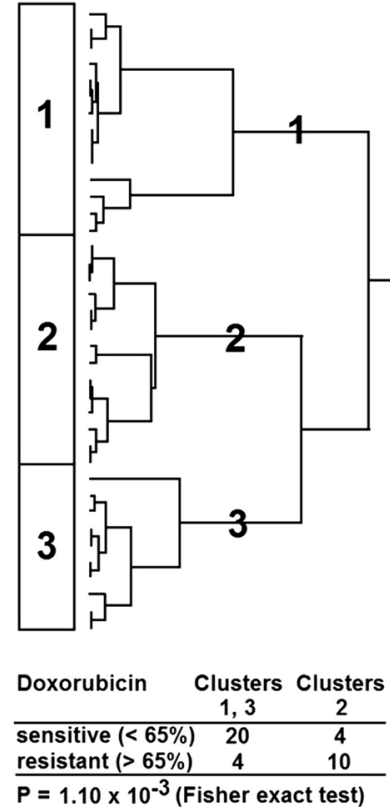

Leukemia

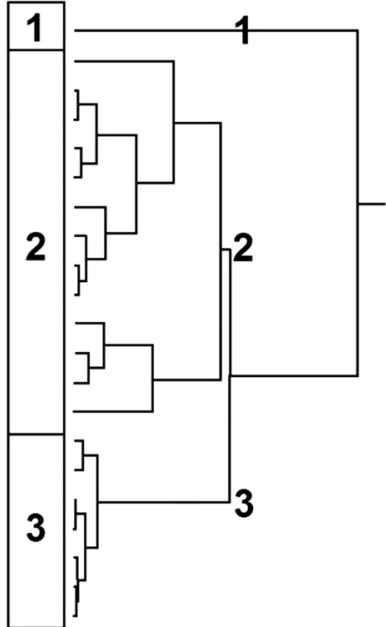

Daunorubicin Clusters Clusters

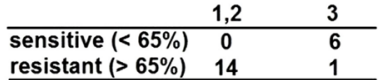

resistant (> 65\%) 14

$P=1.29 \times 10^{-4}$ (Fisher exact test)

FIGURE 3 | (A) Cross-resistance of doxorubicin to daunorubicin, 5-fluorouracil, actinomycin D, and cyclophosphamide in various human tumor types as measured by the in vitro short-term test. (B) Hierarchical cluster analyses of response of clinical tumor specimens toward different antitumor drugs from different drug classes: doxorubicin, daunorubicin (anthracyclines), actinomycion D, bleomycin (antibiotics), 5-fluorouracil, methotrexate (antimetabolites), mitopodozide

(epipodophyllotoxins), and procarbazine, triaziquone (alkylating agents). Dendograms obtained from clustering of 59 diverse tumors, 38 lung carcinomas, and 21 leukemia [data are taken from Ref. (87)]. 
for these analyses was substantiated by the fact that increasing evidence emerged in the literature for a variety of many different drug resistance mechanisms, which are all operative in clinically resistant tumors $(5,13,88,91-100)$. The question arises, as to which resistance factors may be recognized by the in vitro short-term test. Therefore, we determined a total of more than 50 resistance-related factors in 94 human non-small cell lung carcinomas by immunohistochemistry (101). These factors can be categorized as resistance proteins, proliferation-related proteins, oncoproteins and tumor suppressor proteins, proteins regulating apoptosis, and angiogenic factors.

The expression of 28 out of $>50$ proteins significantly correlated with doxorubicin resistance in the in vitro short-term test. Of them, the expression of nine proteins directly correlated and another 19 proteins inversely correlated with resistance to doxorubicin.

Some representative examples are shown in Figures 4A,B. Three examples of resistance proteins that were directly associated with doxorubicin resistance were P-gp, GST-pi, and MT (Figure 4A). These histograms demonstrate that the number of tumors with high protein expression levels (as determined by semi-quantitative immunoscores) increased with doxorubicin resistance.

Figure 4B shows three examples of factors that inversely correlated with resistance, i.e., PCNA, FAS/CD95, and VEGF. Here, rather low than high protein expression was related to doxorubicin resistance. Hence, the number of tumors with high expression of these proteins was higher in sensitive tumors. As a next step, we calculated the mean protein expression values of all sensitive or resistant tumors and plotted them in an oncobiogram. Figure 4C shows a synopsis of all resistance factors that significantly correlated with doxorubicin resistance. It can be clearly seen that the mean expressions of all of these factors were lower in sensitive tumors compared to resistant ones.

These analyses clearly indicate that we have to take multiple rather than single factors into account as mode of action of drug resistance. To prove this assumption, we determined the number of resistant tumors co-expressing more than one resistance factor. Figure 4D shows that the number of resistant tumors expressing four resistance factors was highest, whereas the number of resistant tumors with three, two, one, or no factor was gradually decreasing. This clearly speaks for the multifactorial nature of drug resistance and that single resistance factors are not sufficient to explain resistance phenomena in clinical lung tumors.

In addition, we tested whether combinations of resistance factors may improve the prediction of the degree of resistance. Indeed, the degree of resistance increased with the number of resistance markers (Figure 4E).

\section{CONCLUSION}

Data obtained from multiple sources, including in vitro drug resistance testing, immunohistochemical determination of resistance-related proteins, and clinical data, indicate that no single drug resistance mechanism can explain drug resistance. Resistance mechanisms are numerous and diverse. They depend on the detoxifying capacity of cells, tissue-specific factors, repair capacity, drug delivery, cell proliferation, angiogenesis, apoptosis, and many other factors. Additionally mutation or amplification of specific genes involved in protective pathways as well as the mutation of different oncogene or suppressor genes may be responsible for resistance to chemotherapy. It becomes evident that cancer cells utilize multiple pathways to overcome the cytotoxic effect of drugs used during chemotherapy. Resistance tests should, therefore, recognize these pathways. Our studies attempted to discover the important cellular predictive factors. A key future challenge involves determining the relative contributions of each of these mechanisms.

During the past four decades, various in vitro test procedures have been developed used to test sensitivity or resistance. Kubota and Weisenthal reported on in vitro and in vivo results in 1101 gastrointestinal tumors (67). The correlation of in vitro and in vivo results revealed 215 true-sensitive (S/S), 246 false-sensitive (S/R), 595 true-resistant (R/R), and 45 false-resistant (R/S), resulting in a $47 \%$ true-sensitive rate and a $93 \%$ true-resistant rate. Blumenthal and Goldenberg summarized the correlation of the in vitro results of different assay types with patients' response (6). Of 4092 in vitro assays, 1809 were sensitive and 2283 resistant. The correlation of in vitro and in vivo results showed 1297 true-positive patients, who were sensitive in vitro and respond to therapy (S/S), 512 false-positive, who were sensitive in vitro, but resistant clinically (S/R), 2061 true-negative patients, who were resistant in vitro and did not respond to therapy (R/S), and 222 false-negative patients, who were resistant in vitro but responded clinically $(\mathrm{R} / \mathrm{S})$. The sensitivity was estimated as true in $72 \%$ and the resistance in $90 \%$ of the cases. Our data are in agreement with all these investigations.

Nevertheless, none of these predictive in vitro tests have been clinically established for routine diagnostics. The American Society for Clinical Oncology (ASCO) does not recommend in vitro tests for the prediction of chemosensitivity $(102,103)$. This raises the question as to why clinical translation did not take place, despite numerous investigations speaking for the feasibility of such test systems. An explanation might be the predictive accuracy to detect sensitive and resistant tumors. A close inspection of the data from us and others indicate that independent of the specific test method, drug resistance can be detected with high accuracy (>90\%), whereas drug sensitivity can be detected with true-positive rates of only about $40-70 \%$. Hence, the correct conclusion from these data is that all these methods are not reliable enough as clinically useful chemosensitivity tests. However, at the same time it can be stated that drug resistance can be predicted with high reliability. The reasons for this striking difference in predictive power to distinguish between sensitive and resistant tumors may be numerous.

Chemosensitivity of tumor cells detected ex vivo under artificial laboratory conditions does not necessarily comply with the specific situation of a patient. For instance, effective levels of antineoplastic agents in tumors may not be reached, if tumors are poorly vascularized. Hepatic biotransformation of drugs or interaction between drugs may also play a role in vivo. For these reasons, false-positive results (sensitive in vitro, but resistant in vivo) can be expected to occur more frequently than vice versa. A major concept of all the different predictive in vitro tests was 
A
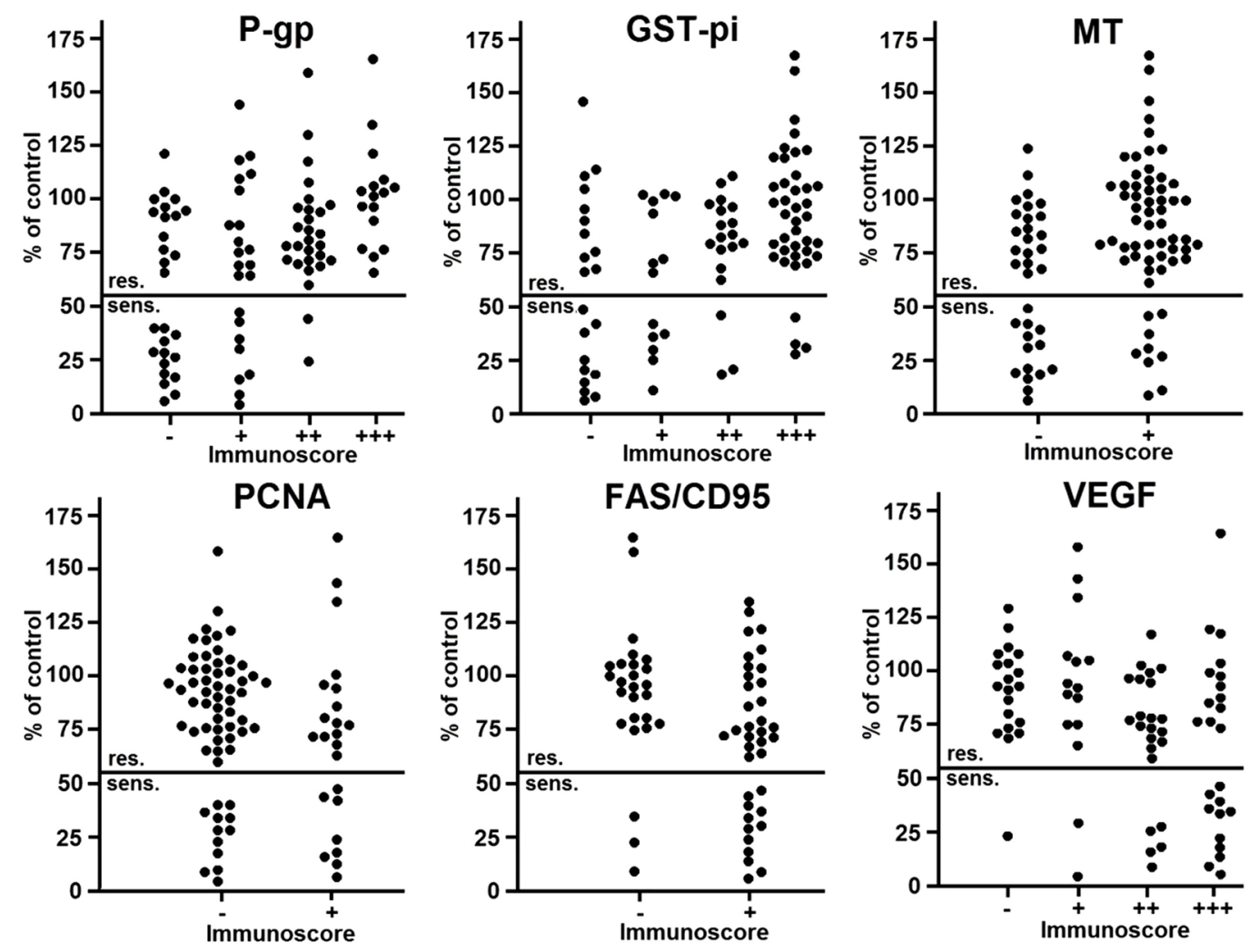

c Oncobiogram
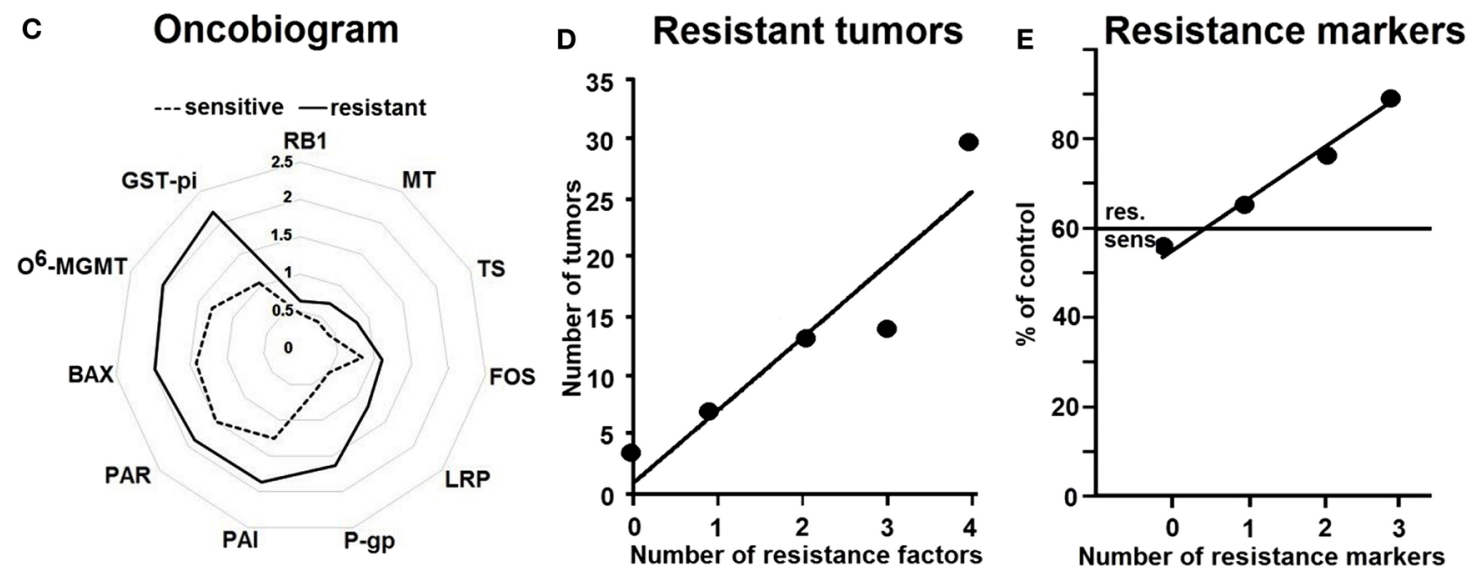

FIGURE 4 | Relationship between the expression of resistance factors in 94 non-small cell lung carcinomas immunohistochemistry and resistance to doxorubicin as determined by the in vitro short-term test. The factors show no reaction $(-)$ weak $(+)$, moderate $(++)$ or strong reaction $(+++)$. (A) Representative examples of factors directly correlating with resistance. (B) Representative examples of factors inversely correlating with resistance. (C) Oncobiogram of resistance factors in sensitive tumors (dotted line) and resistant tumors (bold line). (D) Number of resistant tumors expressing no or one resistance factor or co-expressing two to four factors (P-gp, GST-pi, TS, MT). (E) Number of resistance markers in relationship to the degree of resistance. Abscissa: 0, no resistance marker; 1, one resistance marker, 2, two resistance markers, 3, three resistance markers (P-gp, GST-pi, or TOP2). Ordinate: inhibition by doxorubicin (10 $\mu$ g/ml) as measured by the in vitro short-term test. Abbreviations: P-gp, P-glycoprotein; GST-pi, glutathione S-transferase-pi; MT, metallothionein; PCNA, proliferation cellular nuclear antigen; FAS/CD95, Fas ligand; VEGF, vascular endothelial growth factor; TS, thymidylate synthase; FOS, Fos oncoprotein; LRP, lung resistance protein; $\mathrm{RB} 1$, retinoblastoma protein 1; PAl, plasminogen activator inhibitor; PAR, plasminogen activator receptor; BAX, Bcl2 family member; $\mathrm{O}^{6}$-MGMT, $\mathrm{O}^{6}$-methylguanine DNA-methyltransferase. (Data are taken from Ref. (101)).

to identify drugs a priori which tumors are most sensitive to, in order to use them for subsequent therapy. Hence, scientists and oncologists alike were hunting for the optimal chemosensitivity test. The facts after all these years of research teach us that it may not be possible to find such an optimal test system. Therefore, it is time now to rethink and question this concept. Instead of 
testing chemosensivity, these in vitro tests may be used to identify those tumors that are drug resistant with the aim not to treat them with chemotherapy at all. In the past decades, this option may have appeared less attractive, as oncologists cannot leave patients alone with the message "Sorry, your tumor is resistant, we cannot do anything for you." This is frustrating for both, patients and physicians. Nowadays, the situation is changing, as novel treatment options are emerging. Patients diagnosed as being drug resistant with the help of such predictive tests may be treated with other therapy strategies, such as antibody therapy, adoptive

\section{REFERENCES}

1. Pinedo HM, Giaccone G. Drug Resistance in the Treatment of Cancer. Cambridge: Cambridge University Press (1998).

2. Volm M, Mattern J. Resistance mechanisms and their regulation in lung cancer. Crit Rev Oncog (1996) 7(3-4):227-44. doi:10.1615/CritRevOncog. v7.i3- 4.50

3. Mellor HR, Callaghan R. Resistance to chemotherapy in cancer: a complex and integrated cellular response. Pharmacology (2008) 81(4):275-300. doi:10.1159/000115967

4. Lippert TH, Ruoff HJ, Volm M. Could a revision of the current guidelines for cancer drug use improve the quality of cancer treatment? Ther Clin Risk Manag (2014) 10:69-72. doi:10.2147/tcrm.s51404

5. Mattern J, Volm M. Clinical relevance of predictive tests for cancer chemotherapy. Cancer Treat Rev (1982) 9(4):267-98. doi:10.1016/ S0305-7372(82)80041-8

6. Blumenthal RD, Goldenberg DM. Methods and goals for the use of in vitro and in vivo chemosensitivity testing. Mol Biotechnol (2007) 35(2):185-97. doi:10.1007/BF02686104

7. Volm M, Mattern J, Wayss K. The effects of cytostatic drugs on transplanted tumours. An investigation of the correlation between in vivo and in vitro results. Arch Geschwulstforsch (1974) 43(2):137-44.

8. Volm M, Wayss K, Kaufmann M, Mattern J. Pretherapeutic detection of tumour resistance and the results of tumour chemotherapy. Eur J Cancer (1979) 15(7):983-93. doi:10.1016/0014-2964(79)90282-2

9. Volm M, Lindner C. Detection of induced resistance in short-term-tests. Adriamycin-resistant sarcoma 180. Z Krebsforsch Klin Onkol Cancer Res Clin Oncol (1978) 91(1):1-10. doi:10.1007/BF00305966

10. Volm M, Maas E, Mattern J. Detection of induced resistance to cytosine-arabinoside with a short-term test. Eur J Cancer (1980) 16(5):733-6. doi:10.1016/0014-2964(80)90216-9

11. Volm M, Kleine W, Pfleiderer A. Flow-cytometric prognostic factors for the survival of patients with ovarian carcinoma: a 5-year follow-up study. Gynecol Oncol (1989) 35(1):84-9. doi:10.1016/0090-8258(89)90018-8

12. Volm M, Maas E, Mattern J. In vivo and in vitro detection of induced resistance to daunorubicin in murine leukemia L 1210. Arzneimittelforschung (1981) 31(2):300-2.

13. Valeriote F, van Putten L. Proliferation-dependent cytotoxicity of anticancer agents: a review. Cancer Res (1975) 35(10):2619-30.

14. Volm M, Hahn EW, Mattern J, Muller T, Vogt-Moykopf I, Weber E. Fiveyear follow-up study of independent clinical and flow cytometric prognostic factors for the survival of patients with non-small cell lung carcinoma. Cancer Res (1988) 48(10):2923-8.

15. Cooperative Study Group for sensitivity Testing of Tumors (Goerttler K, Mattern J, Volm M, et al). In vitro short-term test to determine the resistance of human tumors to chemotherapy: group for sensitivity testing of tumors (KSST). Cancer (1981) 48(10):2127-35.

16. Volm M, Drings P, Hahn EW, Mattern J. Prediction of the clinical chemotherapeutic response of stage III lung adenocarcinoma patients by an in vitro short term test. Br J Cancer (1988) 57(2):198-200. doi:10.1038/ bjc. 1988.42

17. Alberts DS, Samon SE, Chen HS, Surwit EA, Soehnlen B, Young L, et al. In-vitro clonogenic assay for predicting response of ovarian cancer to chemotherapy. Lancet (1980) 2(8190):340-2. doi:10.1016/S0140-6736(80)90340-2 immune therapy, hyperthermia, and in the future may be also with aptamer therapy, gene therapy, and others.

\section{ACKNOWLEDGMENTS}

We are thankful for Mrs. Ilona Zirbs for secretarial assistance.

\section{FUNDING}

This paper has been performed with intramural funding.

18. Khoo SK, Hurst T, Webb MJ, Dickie G, Kearsley J, Parsons PG, et al. Clinical value of in vitro drug sensitivity testing based on short-term effects on DNA and RNA metabolism in ovarian cancer. J Surg Oncol (1989) 41(3):201-5. doi:10.1002/jso.2930410314

19. Kern DH, Weisenthal LM. Highly specific prediction of antineoplastic drug resistance with an in vitro assay using suprapharmacologic drug exposures. $J$ Natl Cancer Inst (1990) 82(7):582-8. doi:10.1093/jnci/82.7.582

20. Blackman KE, Fingert HJ, Fuller AF, Meitner PA. The fluorescent cytoprint assay in gynecological malignancies and breast cancer. Methodology and results. Contrib Gynecol Obstet (1994) 19:53-63.

21. Federico M, Alberts DS, Garcia DJ, Emerson J, Fanta P, Liu R, et al. In vitro drug testing of ovarian cancer using the human tumor colony-forming assay: comparison of in vitro response and clinical outcome. Gynecol Oncol (1994) 55(3 Pt 2):S156-63. doi:10.1006/gyno.1994.1356

22. Andreotti PE, Cree IA, Kurbacher CM, Hartmann DM, Linder D, Harel G, et al. Chemosensitivity testing of human tumors using a microplate adenosine triphosphate luminescence assay: clinical correlation for cisplatin resistance of ovarian carcinoma. Cancer Res (1995) 55(22):5276-82.

23. Csoka K, Tholander B, Gerdin E, de la Torre M, Larsson R, Nygren P. In vitro determination of cytotoxic drug response in ovarian carcinoma using the fluorometric microculture cytotoxicity assay (FMCA). Int $J$ Cancer (1997) 72(6):1008-12. doi:10.1002/ (SICI)1097-0215(19970917)72:6<1008::AID-IJC15>3.0.CO;2-0

24. Taylor CG, Sargent JM, Elgie AW, Reid FD, Alton PA, Hill JG. The clinical relevance of chemosensitivity testing in ovarian cancer. Cancer Detect Prev (1998) 22(4):305-12. doi:10.1046/j.1525-1500.1998.CDOA39.x

25. Konecny G, Crohns C, Pegram M, Felber M, Lude S, Kurbacher C, et al. Correlation of drug response with the ATP tumorchemosensitivity assay in primary FIGO stage III ovarian cancer. Gynecol Oncol (2000) 77(2):258-63. doi:10.1006/gyno.2000.5728

26. Taylor CG, Sargent JM, Elgie AW, Williamson CJ, Lewandowicz GM, Chappatte $\mathrm{O}$, et al. Chemosensitivity testing predicts survival in ovarian cancer. Eur J Gynaecol Oncol (2001) 22(4):278-82.

27. Hetland TE, Kaern J, Skrede M, Sandstad B, Trope C, Davidson B, et al. Predicting platinum resistance in primary advanced ovarian cancer patients with an in vitro resistance index. Cancer Chemother Pharmacol (2012) 69(5):1307-14. doi:10.1007/s00280-012-1835-9

28. Neubauer H, Stefanova M, Solomayer E, Meisner C, Zwirner M, Wallwiener $\mathrm{D}$, et al. Predicting resistance to platinum-containing chemotherapy with the ATP tumor chemosensitivity assay in primary ovarian cancer. Anticancer Res (2008) 28(2A):949-55.

29. Arienti C, Tesei A, Verdecchia GM, Framarini M, Virzi S, Grassi A, et al. Role of conventional chemosensitivity test and tissue biomarker expression in predicting response to treatment of peritoneal carcinomatosis from colon cancer. Clin Colorectal Cancer (2013) 12(2):122-7. doi:10.1016/j. clcc.2012.11.006

30. Daidone MG, Silvestrini R, Sanfilippo O, Zaffaroni N, Varini M, De Lena M. Reliability of an in vitro short-term assay to predict the drug sensitivity of human breast cancer. Cancer (1985) 56(3):450-6. doi:10.1002/1097-0142(19850801)56:3<450::AID-CNCR2820560306>3.0.CO;2-V

31. Kochli OR, Sevin BU, Averette HE, Haller U. Overview of currently used chemosensitivity test systems in gynecologic malignancies and breast cancer. Contrib Gynecol Obstet (1994) 19:12-23. 
32. Elledge RM, Clark GM, Hon J, Thant M, Belt R, Maguire YP, et al. Rapid in vitro assay for predicting response to fluorouracil in patients with metastatic breast cancer. J Clin Oncol (1995) 13(2):419-23.

33. Xu JM, Song ST, Tang ZM, Liu XQ, Jiang ZF, Zhou L, et al. Evaluation of in vitro chemosensitivity of antitumor drugs using the MTT assay in fresh human breast cancer. Breast Cancer Res Treat (1998) 49(3):251-9. doi:10.10 23/A:1006019614543

34. Xu JM, Song ST, Tang ZM, Jiang ZF, Liu XQ, Zhou L, et al. Predictive chemotherapy of advanced breast cancer directed by MTT assay in vitro. Breast Cancer Res Treat (1999) 53(1):77-85. doi:10.1023/A:1006122912146

35. Eidtmann H, Jonat W, Maass H. Chemosensibilitätstestung gynäkologischer Tumoren mittels 'Volm'-Test und Stammzell-Assay. New York, NY: Georg Thieme Verlag Stuttgart (1985).

36. Khoo SK, Hurst T, Webb MJ, Mackay EV. Short-term in vitro chemosensitivity testing of tumours of the ovary, cervix and uterus. Measurement of DNA metabolism by $3 \mathrm{H}$ thymidine incorporation. Aust N Z J Obstet Gynaecol (1986) 26(4):288-94. doi:10.1111/j.1479-828X.1986.tb01591.x

37. O’Toole SA, Sheppard BL, McGuinness EP, Gleeson NC, Yoneda M, Bonnar $\mathrm{J}$. The MTS assay as an indicator of chemosensitivity/resistance in malignant gynaecological tumours. Cancer Detect Prev (2003) 27(1):47-54. doi:10.1016/ S0361-090X(02)00171-X

38. Kim JH, Lee KW, Kim YH, Lee KH, Oh do Y, Kim J, et al. Individualized tumor response testing for prediction of response to paclitaxel and cisplatin chemotherapy in patients with advanced gastric cancer. J Korean Med Sci (2010) 25(5):684-90. doi:10.3346/jkms.2010.25.5.684

39. Kawamura H, Ikeda K, Takiyama I, Terashima M. The usefulness of the ATP assay with serum-free culture for chemosensitivity testing of gastrointestinal cancer. Eur J Cancer (1997) 33(6):960-6. doi:10.1016/ S0959-8049(97)00075-0

40. Hirai T, Kawano K, Hirabayashi N, Nishiyama M, Yamashita Y, Mukaida $\mathrm{H}$, et al. A novel in vitro chemosensitivity test using materials collected by endoscopic biopsy. Anticancer Drugs (1991) 2(3):269-74. doi:10.1097/00001813-199106000-00008

41. Link KH, Aigner KR, Kuehn W, Schwemmle K, Kern DH. Prospective correlative chemosensitivity testing in high-dose intraarterial chemotherapy for liver metastases. Cancer Res (1986) 46(9):4837-40.

42. Link KH, Kornmann M, Butzer U, Leder G, Sunelaitis E, Pillasch J, et al. Thymidylate synthase quantitation and in vitro chemosensitivity testing predicts responses and survival of patients with isolated nonresectable liver tumors receiving hepatic arterial infusion chemotherapy. Cancer (2000) 89(2):288-96. doi:10.1002/1097-0142(20000715)89:2<288::AID-CNCR13>3.0.CO;2-O

43. Tveit KM, Gundersen S, Hoie J, Pihl A. Predictive chemosensitivity testing in malignant melanoma: reliable methodology - ineffective drugs. Br J Cancer (1988) 58(6):734-7. doi:10.1038/bjc.1988.299

44. Ugurel S, Schadendorf D, Pfohler C, Neuber K, Thoelke A, Ulrich J, et al. In vitro drug sensitivity predicts response and survival after individualized sensitivity-directed chemotherapy in metastatic melanoma: a multicenter phase II trial of the Dermatologic Cooperative Oncology Group. Clin Cancer Res (2006) 12(18):5454-63. doi:10.1158/1078-0432.ccr-05-2763

45. Kitten CM, Von Hoff DD, Bennett EV Jr, Trinkle JK, Grover FL. The human tumor clonogenic assay in the treatment of patients with lung cancer. Ann Thorac Surg (1983) 36(4):408-10. doi:10.1016/S0003-4975(10)60478-X

46. Bertelsen CA, Kern DH, Kaiser LR, Mann BD, Holmes EC, Morton DL. Biopsy of thoracic neoplasms for assay of chemosensitivity. New indication for thoracotomy. Arch Surg (1983) 118(9):1074-6. doi:10.1001/ archsurg.1983.01390090058013

47. Gazdar AF, Steinberg SM, Russell EK, Linnoila RI, Oie HK, Ghosh BC, et al. Correlation of in vitro drug-sensitivity testing results with response to chemotherapy and survival in extensive-stage small cell lung cancer: a prospective clinical trial. J Natl Cancer Inst (1990) 82(2):117-24. doi:10.1093/ jnci/82.2.117

48. Kawamura M, Gika M, Abiko T, Inoue Y, Oyama T, Izumi Y, et al. Clinical evaluation of chemosensitivity testing for patients with unresectable non-small cell lung cancer (NSCLC) using collagen gel droplet embedded culture drug sensitivity test (CD-DST). Cancer Chemother Pharmacol (2007) 59(4):507-13. doi:10.1007/s00280-006-0292-8

49. Alonso K. Human tumor stem cell assay. A prospective clinical trial. Cancer (1984) 54(11):2475-9.
50. Iwadate Y, Fujimoto S, Yamaura A. Differential chemosensitivity in human intracerebral gliomas measured by flow cytometric DNA analysis. Int J Mol Med (2002) 10(2):187-92.

51. Hwang WS, Chen LM, Huang SH, Wang CC, Tseng MT. Prediction of chemotherapy response in human leukemia using in vitro chemosensitivity test. Leuk Res (1993) 17(8):685-8. doi:10.1016/0145-2126(93)90074-U

52. Durie BG, Young LA, Salmon SE. Human myeloma in vitro colony growth: interrelationships between drug sensitivity, cell kinetics, and patient survival duration. Blood (1983) 61(5):929-34.

53. Sondak VK, Bertelsen CA, Tanigawa N, Hildebrand-Zanki SU, Morton DL, Korn EL, et al. Clinical correlations with chemosensitivities measured in a rapid thymidine incorporation assay. Cancer Res (1984) 44(4):1725-8.

54. Wada T, Akiyoshi T, Nakamura Y. A simplified tritiated thymidine incorporation assay for chemosensitivity testing of human tumors. Eur J Cancer Clin Oncol (1988) 24(9):1421-4. doi:10.1016/0277-5379(88)90331-8

55. Kobayashi H, Tanisaka K, Doi O, Kodama K, Higashiyama M, Nakagawa H, et al. An in vitro chemosensitivity test for solid human tumors using collagen gel droplet embedded cultures. Int J Oncol (1997) 11(3):449-55.

56. Fiebig HH, Maier A, Burger AM. Clonogenic assay with established human tumour xenografts: correlation of in vitro to in vivo activity as a basis for anticancer drug discovery. Eur J Cancer (2004) 40(6):802-20. doi:10.1016/j.ejca.2004.01.009

57. Grigsby PW, Zighelboim I, Powell MA, Mutch DG, Schwarz JK. In vitro chemoresponse to cisplatin and outcomes in cervical cancer. Gynecol Oncol (2013) 130(1):188-91. doi:10.1016/j.ygyno.2013.04.005

58. Salmon SE, Alberts DS, Durie BG, Meyskens FL, Jones SE, Soehnlen B, et al. Clinical correlations of drug sensitivity in the human tumor stem cell assay. RecentResultsCancerRes(1980)74:300-5.doi:10.1007/978-3-642-81488-4_36

59. Bertelsen CA, Sondak VK, Mann BD, Korn EL, Kern DH. Chemosensitivity testing of human solid tumors. A review of 1582 assays with 258 clinical correlations. Cancer (1984) 53(6):1240-5. doi:10.1002/10970142(19840315)53:6<1240::AID-CNCR2820530604>3.0.CO;2-Y

60. Salmon SE. Human tumor colony assay and chemosensitivity testing. Cancer Treat Rep (1984) 68(1):117-25.

61. Kimmel DW, Shapiro JR, Shapiro WR. In vitro drug sensitivity testing in human gliomas. J Neurosurg (1987) 66(2):161-71. doi:10.3171/ jns.1987.66.2.0161

62. Bogden AE, Cobb WR. The subrenal capsule assay (SRCA). Eur J Cancer Clin Oncol (1986) 22(9):1033-6. doi:10.1016/0277-5379(86)90002-7

63. Von Hoff DD, Sandbach JF, Clark GM, Turner JN, Forseth BF, Piccart MJ, et al. Selection of cancer chemotherapy for a patient by an in vitro assay versus a clinician. J Natl Cancer Inst (1990) 82(2):110-6. doi:10.1093/jnci/82.2.110

64. Meitner PA. The fluorescent cytoprint assay: a new approach to in vitro chemosensitivity testing. Oncology (Williston Park) (1991) 5(9):75-81. discussion 81-2, 85, 88.

65. Kondo T, Kubota T, Tanimura H, Yamaue H, Akiyama S, Maehara Y, et al. Cumulative results of chemosensitivity tests for antitumor agents in Japan. Japan Research Society for appropriate cancer chemotherapy. Anticancer Res (2000) 20(4):2389-92.

66. Kobayashi H. Development of a new in vitro chemosensitivity test using collagen gel droplet embedded culture and image analysis for clinical usefulness. RecentResultsCancerRes (2003) 161:48-61.doi:10.1007/978-3-642-19022-3_5

67. Kubota T, Weisenthal L. Chemotherapy sensitivity and resistance testing: to be "standard" or to be individualized, that is the question. Gastric Cancer (2006) 9(2):82-7. doi:10.1007/s10120-006-0366-7

68. Weisenthal LM, Nygren P. Current status of cell culture drug resistance testing (CCDRT). May (2002). Available from: https://www.researchgate.net/ publication/237347352 (retrieved December 8th 2015).

69. Holloway RW, Mehta RS, Finkler NJ, Li KT, McLaren CE, Parker RJ, et al. Association between in vitro platinum resistance in the EDR assay and clinical outcomes for ovarian cancer patients. Gynecol Oncol (2002) 87(1):8-16. doi:10.1006/gyno.2002.6797

70. Nakada S, Aoki D, Ohie S, Horiuchi M, Suzuki N, Kanasugi M, et al. Chemosensitivity testing of ovarian cancer using the histoculture drug response assay: sensitivity to cisplatin and clinical response. Int J Gynecol Cancer (2005) 15(3):445-52. doi:10.1111/j.1525-1438.2005.15307.x

71. Herzog TJ, Krivak TC, Fader AN, Coleman RL. Chemosensitivity testing with ChemoFx and overall survival in primary ovarian cancer. Am J Obstet Gynecol (2010) 203(1):e1-6. doi:10.1016/j.ajog.2010.01.059 
72. Jung PS, Kim DY, Kim MB, Lee SW, Kim JH, Kim YM, et al. Progressionfree survival is accurately predicted in patients treated with chemotherapy for epithelial ovarian cancer by the histoculture drug response assay in a prospective correlative clinical trial at a single institution. Anticancer Res (2013) 33(3):1029-34.

73. Xu X, Dai H, Zhao Y, Wang Y, Qian Z, Chen X. In vitro chemosensitivity assay of ascites in epithelial ovarian cancer. Eur J Gynaecol Oncol (2013) 34(6):559-64

74. Isogai A, Nagaya M, Matsuoka H, Watanabe T, Tsukikawa S, Kubota S. A new chemosensitivity assay for ascites tumor cells using a thermoreversible gelation polymer as a culture medium and the observed clinical responses. Eur Surg Res (2007) 39(1):41-50. doi:10.1159/000098439

75. Kubota T, Sasano N, Abe O, Nakao I, Kawamura E, Saito T, et al. Potential of the histoculture drug-response assay to contribute to cancer patient survival. Clin Cancer Res (1995) 1(12):1537-43.

76. Furukawa T, Kubota T, Hoffman RM. Clinical applications of the histoculture drug response assay. Clin Cancer Res (1995) 1(3):305-11.

77. Abe S, Kubota T, Matsuzaki SW, Otani Y, Watanabe M, Teramoto T, et al. Chemosensitivity test is useful in evaluating the appropriate adjuvant cancer chemotherapy for stage III non-scirrhous and scirrhous gastric cancers. Anticancer Res (1999) 19(5C):4581-6.

78. Kodera Y, Ito S, Fujiwara M, Mochizuki Y, Ohashi N, Ito Y, et al. In vitro chemosensitivity test to predict chemosensitivity for paclitaxel, using human gastric carcinoma tissues. Int J Clin Oncol (2006) 11(6):449-53. doi:10.1007/ s10147-006-0618-x

79. Wu KM, Ghantous H, Birnkrant DB. Current regulatory toxicology perspectives on the development of herbal medicines to prescription drug products in the United States. Food Chem Toxicol (2008) 46(8):2606-10. doi:10.1016/j. fct.2008.05.029

80. Kubota T, Otani Y, Furukawa T, Hasegawa H, Watanabe M, Kitajima M. Chemosensitivity testing - present and future in Japan. Recent Results Cancer Res (2003) 161:231-41. doi:10.1007/978-3-642-19022-3_18

81. Kabeshima Y, Kubota T, Watanabe M, Hasegawa H, Furukawa T, Kitajima M. Clinical usefulness of chemosensitivity test for advanced colorectal cancer. Anticancer Res (2002) 22(5):3033-7.

82. Yamaue H, Tani M, Onishi H, Kinoshita H, Nakamori M, Yokoyama S, et al. Locoregional chemotherapy for patients with pancreatic cancer intra-arterial adjuvant chemotherapy after pancreatectomy with portal vein resection. Pancreas (2002) 25(4):366-72. doi:10.1097/00006676-200211000-00008

83. Michalski CW, Erkan M, Sauliunaite D, Giese T, Stratmann R, Sartori C, et al. Ex vivo chemosensitivity testing and gene expression profiling predict response towards adjuvant gemcitabine treatment in pancreatic cancer. $\mathrm{Br} \mathrm{J}$ Cancer (2008) 99(5):760-7. doi:10.1038/sj.bjc.6604528

84. Nakamori M, Iwahashi M, Nakamura M, Yamaue H. Clinical benefit of chemosensitivity test for patients with regional lymph node-positive esophageal squamous cell carcinoma. J Surg Oncol (2003) 84(1):10-6. doi:10.1002/ jso. 10286

85. Doerler M, Hyun J, Venten I, Potthoff A, Bartke U, Serova K, et al. Does chemosensitivity-assay-directed therapy have an influence on the prognosis of patients with malignant melanoma stage IV? A retrospective study of 14 patients with malignant melanoma stage IV. Eur J Med Res (2007) 12(10):497-502.

86. Mollgard L, Tidefelt U, Sundman-Engberg B, Lofgren C, Paul C. In vitro chemosensitivity testing in acute non lymphocytic leukemia using the bioluminescence ATP assay. Leuk Res (2000) 24(5):445-52. doi:10.1016/ S0145-2126(00)00003-5

87. Efferth T, Konkimalla VB, Wang YF, Sauerbrey A, Meinhardt S, Zintl F, et al. Prediction of broad spectrum resistance of tumors towards anticancer drugs. Clin Cancer Res (2008) 14(8):2405-12. doi:10.1158/1078-0432. ccr-07-4525

88. Bradley G, Juranka PF, Ling V. Mechanism of multidrug resistance. Biochim Biophys Acta (1988) 948(1):87-128.

89. Volm M. Multidrug resistance and its reversal. Anticancer Res (1998) 18(4C):2905-17.

90. Borst P. Cancer drug pan-resistance: pumps, cancer stem cells, quiescence, epithelial to mesenchymal transition, blocked cell death pathways, persisters or what? Open Biol (2012) 2(5):120066. doi:10.1098/rsob.120066

91. Washtien WL. Thymidylate synthetase levels as a factor in 5-fluorodeoxyuridine and methotrexate cytotoxicity in gastrointestinal tumor cells. $\mathrm{Mol}$ Pharmacol (1982) 21(3):723-8.

92. Schimke RT. Gene amplification in cultured animal cells. Cell (1984) 37(3):705-13. doi:10.1016/0092-8674(84)90406-9

93. Kelley SL, Basu A, Teicher BA, Hacker MP, Hamer DH, Lazo JS. Overexpression of metallothionein confers resistance to anticancer drugs. Science (1988) 241(4874):1813-5. doi:10.1126/science.3175622

94. Scanlon KJ, Kashani-Sabet M. Elevated expression of thymidylate synthase cycle genes in cisplatin-resistant human ovarian carcinoma A2780 cells. Proc Natl Acad Sci U S A (1988) 85(3):650-3. doi:10.1073/ pnas.85.3.650

95. Whelan RD, Hosking LK, Townsend AJ, Cowan KH, Hill BT. Differential increases in glutathione $\mathrm{S}$-transferase activities in a range of multidrug-resistant human tumor cell lines. Cancer Commun (1989) 1(6):359-65.

96. Pegg AE. Mammalian O6-alkylguanine-DNA alkyltransferase: regulation and importance in response to alkylating carcinogenic and therapeutic agents. Cancer Res (1990) 50(19):6119-29.

97. Volm M, Mattern J, Samsel B. Overexpression of P-glycoprotein and glutathione S-transferase-pi in resistant non-small cell lung carcinomas of smokers. Br J Cancer (1991) 64(4):700-4. doi:10.1038/bjc.1991.384

98. Teicher BA. Hypoxia and drug resistance. Cancer Metastasis Rev (1994) 13(2):139-68. doi:10.1007/BF00689633

99. Koomagi R, Mattern J, Volm M. Up-regulation of resistance-related proteins in human lung tumors with poor vascularization. Carcinogenesis (1995) 16(9):2129-33. doi:10.1093/carcin/16.9.2129

100. Hickman JA. Apoptosis and chemotherapy resistance. Eur J Cancer (1996) 32A(6):921-6. doi:10.1016/0959-8049(96)00080-9

101. Volm M, Rittgen W. Cellular predictive factors for the drug response of lung cancer. Anticancer Res (2000) 20(5B):3449-58.

102. Schrag D, Garewal HS, Burstein HJ, Samson DJ, Von Hoff DD, Somerfield MR. American Society of Clinical Oncology Technology assessment: chemotherapy sensitivity and resistance assays. J Clin Oncol (2004) 22(17):3631-8. doi:10.1200/JCO.2004.05.065

103. Burstein HJ, Mangu PB, Somerfield MR, Schrag D, Samson D, Holt L, et al. American Society of Clinical Oncology clinical practice guideline update on the use of chemotherapy sensitivity and resistance assays. J Clin Oncol (2011) 29(24):3328-30. doi:10.1200/jco.2011.36.0354

Conflict of Interest Statement: The authors declare that the research was conducted in the absence of any commercial or financial relationships that could be construed as a potential conflict of interest.

Copyright (c) 2015 Volm and Efferth. This is an open-access article distributed under the terms of the Creative Commons Attribution License (CC BY). The use, distribution or reproduction in other forums is permitted, provided the original author(s) or licensor are credited and that the original publication in this journal is cited, in accordance with accepted academic practice. No use, distribution or reproduction is permitted which does not comply with these terms. 